\title{
Key risk index identification of UHV project construction based on improved rough set model
}

\author{
Sen Guo*, Huiru Zhao \\ School of Economics and Management, North China Electric Power University, Changping District, Beijing 102206, China
}

Email address:

guosen324@163.com (Sen Guo), guosen@ncepu.edu.cn (Sen Guo)

\section{To cite this article:}

Sen Guo, Huiru Zhao. Key Risk Index Identification of UHV Project Construction Based on Improved Rough Set Model. Science Journal of Energy Engineering. Special Issue: Soft Computing Techniques for Energy Engineering. Vol. 3, No. 4-1, 2015, pp. 6-13.

doi: $10.11648 /$ j.sjee.s.2015030401.12

\begin{abstract}
Compared with the conventional power grid project, the UHV project construction faces more challenges and risks. Identifying the key risk indicators of UHV project construction can improve the level of project risk management and reduce risk-related loss. Taken the data missing of risk indicators into consideration, an improved rough set model for key risk indicators identification of UHV project construction is employed with the introduction of information content. Firstly, the information content of conditional attributes set and information significance of each conditional attribute are calculated; Secondly, the reduced core attribute matrix is formed; Then, the discernibility matrix is built; Finally, the final core attribute set is determined. After building the risk index system, the key risk indicators identification of a certain UHV project construction is performed. The calculation result shows that "land requisition and logging policy risk", "project security management risk" and "land requisition, removing and crop compensation risk" are the key risk indicators.
\end{abstract}

Keywords: UHV Project Construction, Key Risk Indicators, Index Identification, Improved Rough Set Model

\section{Introduction}

Currently, the long-distance and high-capacity transmission capacity of $500 \mathrm{kV}$ power grid in China is limited. The electricity energy produced by the Northwest coal base and Southwestern hydropower base cannot be delivered to the load-intensive eastern regions of China in a cost-effective manner. In this case, the eastern region of China has to construct coal base to meet the electricity demand, which exacerbates the tensions of coal supply and transportation. Therefore, build the UHV transmission systems with the characteristics of large-capacity, long-distance and low-loss transmission capacity will be conducive to the intensive development of China's large coal, large hydro and nuclear power base, which can also optimize the layout of energy production and consumption and promote the coordinated development of regional economy [1]. The UHV construction holds the characteristics of tight time, heavy task, difficult construction and complicated environment, which face many issues, such as difficult stakeholder coordination, tight local government relations, and so on [2]. Compared with the conventional construction projects, the UHV construction project faces more challenges and risks. Therefore, to identify the key risk indicators of
UHV project construction can provide some references for the project risk management, improve risk management level, and reduce the risk loss during the UHV construction process.

Currently, there are some researchers that employ the Multiple Attribute Decision Making (MADM) to evaluate the risk of some engineering construction projects. Ref. [3] used the AHP and Monte Carlo simulation method to evaluate the water conservancy construction risk; Ref. [4] applied expert investigation and AHP method to evaluate the subway construction risk; Ref. [5] identified the risk of oil pipeline construction by using catastrophe progression evaluation method. With respect to the power grid construction, most research papers mainly focus on power grid project management. Ref. [6] built the smart grid project management model using System Dynamics; Ref. [7] studied the application of project file management network system on the power grid construction projects; Ref. [8-9] introduced the typical design overview of American transmission line, the typical design overview of France and South Korea transformer substations, and the inspiration for the design and construction of China's power grid project. With respect 
to the power grid construction risk, the current research literatures are relatively few. Ref. [2] employed the AHP and FCE method to evaluate the risk of UHV power transmission construction project; Ref. [10] studied the power transmission and distribution project construction risk by employing the Fault Tree and Set Pair Analysis theory; Ref. [11] analyzed the risk factors in various stages of power transmission and distribution projects from the perspective of power grid enterprise, and then proposed a checklist of risk factors.

With respect to UHV project, to the best of our knowledge, the current research mainly focuses on the technical aspect other than management aspect, such as the power calculation method of UHV power transmission lines [12], the wind load transferring mechanism in the UHV transmission tower-line system [13], and so on. Therefore, it is very necessary to explore the research related to the risk management of UHV construction project.

In this paper, the key risk indicators of UHV project construction were identified based on Improved Rough Set Model (IRS). Taken a $1000 \mathrm{kV}$ UHV construction project as the example, the risk index system was firstly built, and then the IRS method was employed to identify the key index. The risk identification result can provide some references for the UHV construction management, which can also improve the risk management level and reduce the risk loss.

\section{Risk Index System of UHV Project Construction}

When building the risk index system of UHV project construction, the basic principles of scientific, comprehensiveness, hierarchy and operability should be adopted. Meanwhile, the characteristics of UHV project construction should also be considered. This paper combined the Checklist method and Delphi method to find out the important risk index, and then built the risk index system of UHV project construction. The built risk index system of UHV project construction is shown in Fig. 1, which includes 5 first-level risk criteria and 12 second-level risk indicators.

\section{The Basic Theory of Improved Rough Set Model}

\subsection{Rough Set Theory}

The rough set theory $(R S)$, proposed by Polish computer scientist Zdzisław I. Pawlak in 1982, is a kind of mathematic analysis methods which can describe the incompleteness, inaccuracy and uncertainty. The rough set theory can effectively analyze the random information with the inconsistent and inaccurate characteristics, and can also reason the data to explore the implicit potential law of data without any priori information $[14,15]$. Owing to the above merit, the rough set theory has been applied in the field of electricity, such as the fault diagnosis rule extraction of power grid [16], fault diagnosis of transformer substation [17], multi-objective power grid planning optimization model [18], and so on.

Let the nonempty set $U$ be a finite set, called domain field, and $R$ be an equivalence relation on $U$. For any subset $X \in U$, the pair $T=(U, R)$ is called an approximation space.

Define two subsets:

$$
\underline{R} X=\left\{x \in U \mid[x]_{R} \subseteq X\right\} ; \bar{R} X=\left\{x \in U \mid[x]_{R} \bigcap X \neq \phi\right\}
$$

are called the R-lower and R-upper approximation of $\mathrm{X}$, respectively.

$$
B N_{R}(X)=\bar{R} X-\underline{R} X
$$

is called $R$-boundary region of X. If $B N_{R}(X)=0$, this set is a crisp set, and if $B N_{R}(X)>0$, this set is a rough set.

$\operatorname{POS}_{R}(X)=\underline{R} X$ denotes the $R$-positive region of $X$, just as shown in blackened cells in Fig. 2. $N E G_{R}(X)=U-\bar{R} X$ denotes the $R$-negative region of $X$, just as shown in the white cells in Fig. 2. The relationship between different sets in $R S$ is shown in Fig. 2.

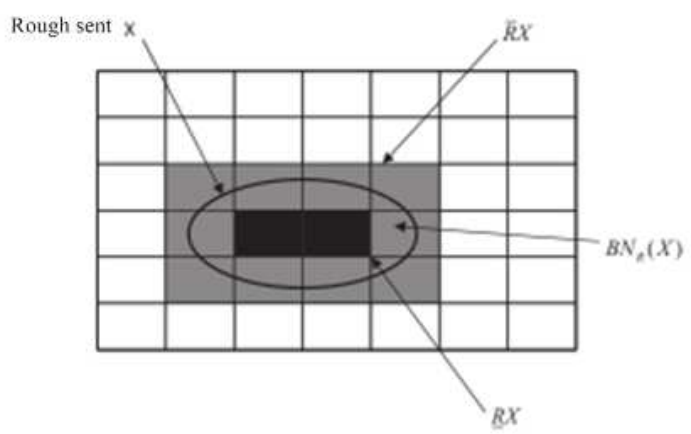

Figure 2. Schematic diagram of rough set theory.

4-tuple $\quad S=(U, C \bigcup D, V, f) \quad$ denotes a knowledge representation system. Of which, $U$ is the universe; $C$ and $D$ are the conditional and decision attribute sets for $U$; is the value range of attribute $a ; f: U \times(C \bigcup D) \rightarrow V$ is an information function, which assigns information value to each object property according to certain rules, namely $\forall x \in U$, if $a \in C \bigcup D$, then $f(x, a) \in V_{a}$.

\subsection{Improved Rough Set Mode}

When there is missing information at the risk information system decision table of UHV construction, the conventional rough set theory cannot be used to explore the potential information of data. When performing the questionnaire, the respondents sometimes maybe miss to give the evaluation scores on some risk indicators, which will lead to the missing information at the information system decision table. Bai C and Sarkis J proposed an improved rough set (IRS) model with the introduction of 'information capacity' concept to overcome this issue [19]. This paper employed the IRS 
model to identify the key indicators of UHV project construction.

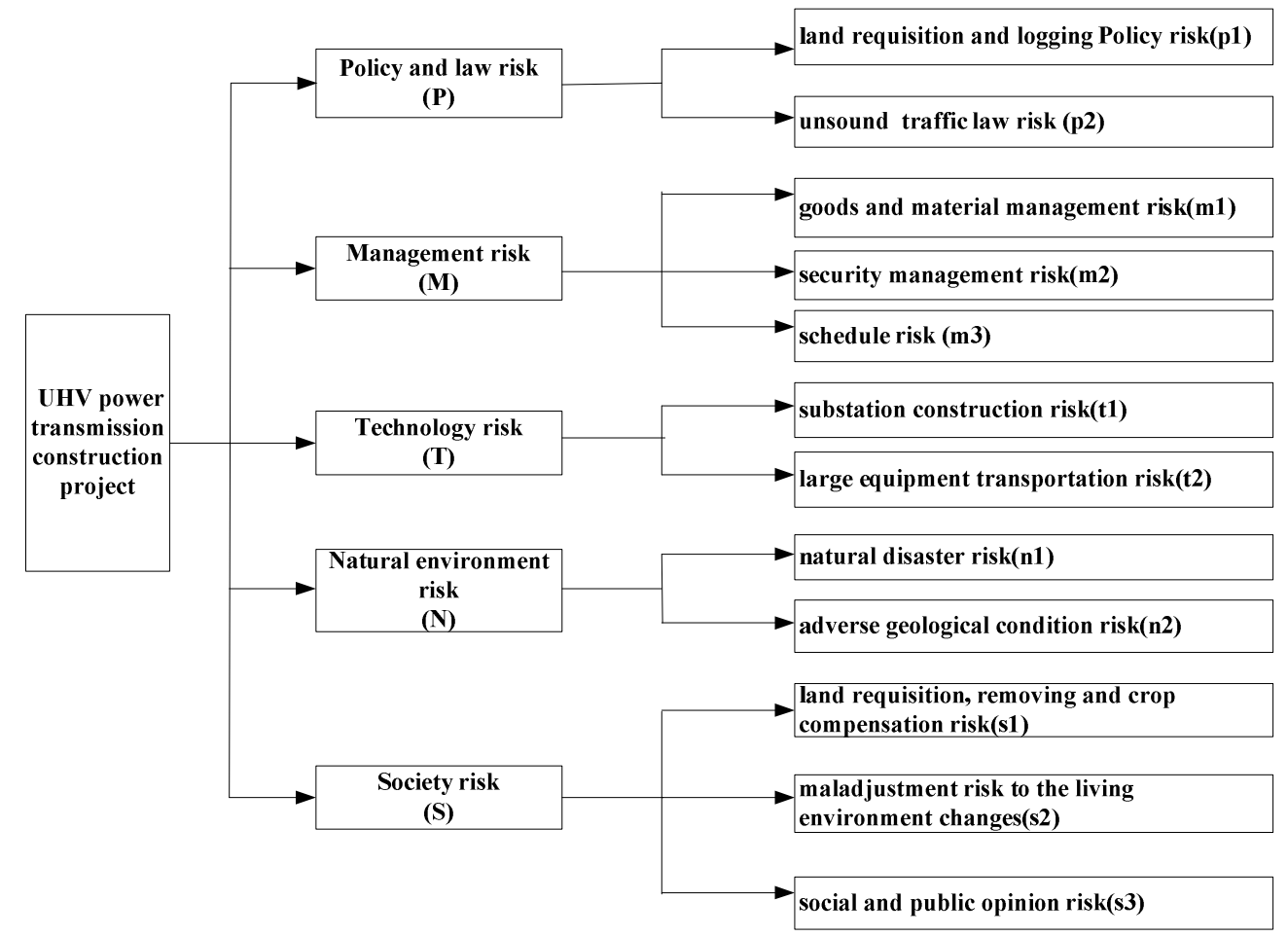

Figure 1. Risk index system of UHV project construction
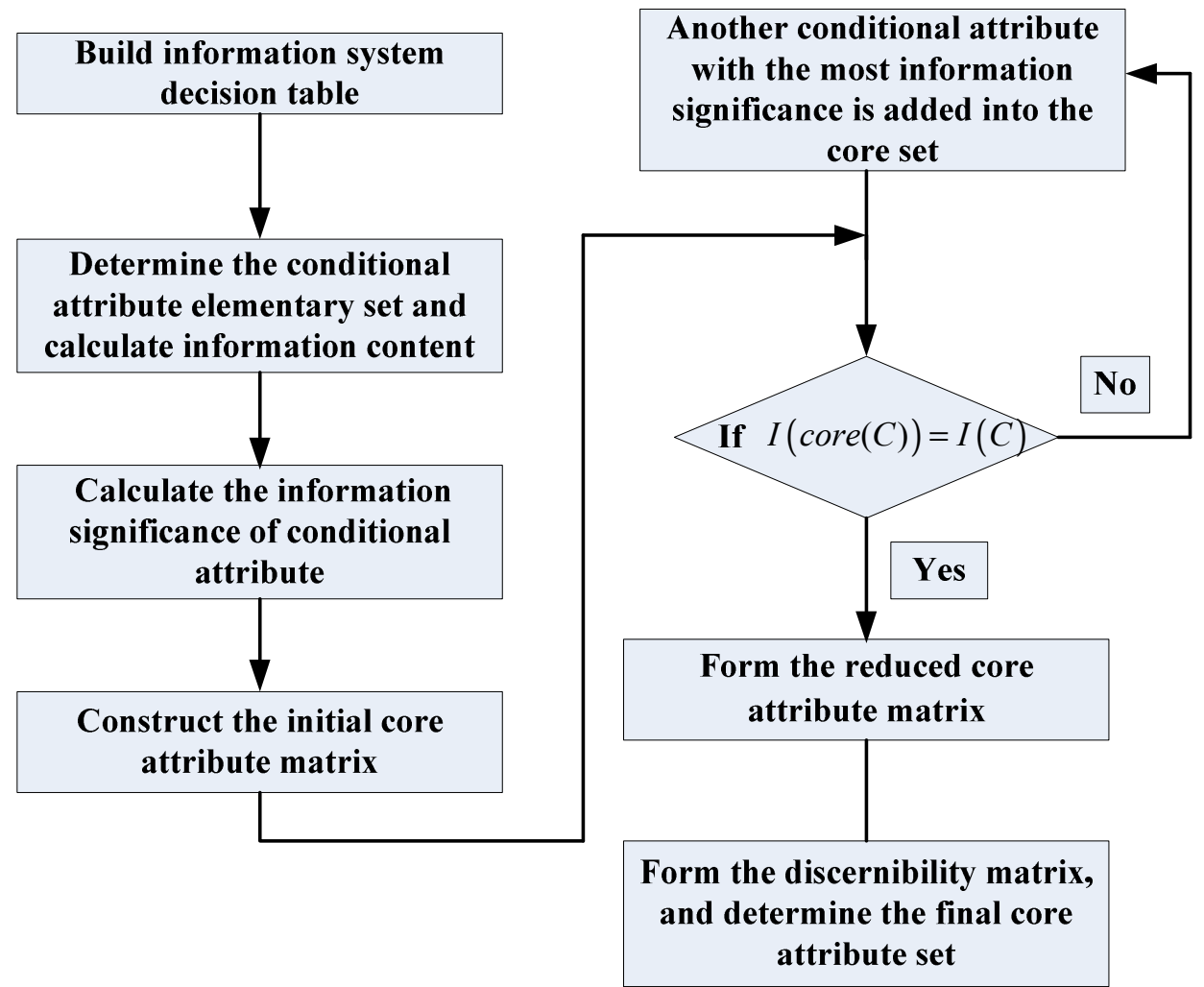

Figure 3. Calculation flow chart of improved rough set model.

The concept steps of employing IRS model to identify the key indicators of UHV project construction are as follows.

Step 1: Build the information system decision table

According to the goal of research object and the relative evaluation index system, the information system decision table is built, which includes the missing information, denoted by '*'.

Step 2: Determine the conditional attribute elementary set 
and calculate information content

The set consisted of objects with the same conditional attribute value is called conditional attribute elementary set.

$$
\operatorname{SIM}(C)=\{(i, j) \in U \times U \mid \forall c \in C, c(i)=c(j), \text { or } c(i)=* \text {, or } c(j)=*\}
$$

where $c(i)$ and $c(j)$ denote the value of conditional attribute $c$ for object $i$ and $j$; $\mathrm{C}$ is the conditional attribute set; ${ }^{*}$ denotes the value missing of conditional attribute.

At the information system decision table, the information capacity of conditional attribute can be calculated by Equation (4).

$$
I(C)=1-\frac{1}{|U|^{2}} \sum_{i=1}^{|U|}\left|X_{i}\right|
$$

where $I(C)$ is the information capacity of conditional attribute; $|U|$ is the total number of all the objects; $\left|X_{i}\right|$ is the number of objects with similar attributes levels across all the conditional attributes for object $i$.

Step 3: Calculate the information significance of conditional attribute

The information significance of conditional attribute will help to reduce the unimportant or irrelevant conditional attribute and save the conditional attribute that has close relationship with the decision attribute [20]. The information significance $\operatorname{Sig}_{C \backslash\{c\}}(c)$ of conditional attribute can be calculated by Equation (5)

$$
\operatorname{Sig}_{C \backslash\{c\}}(c)=I(C)-I(C \backslash\{c\})
$$

Equation (5) identifies the difference between the information content of the full set and the information content of the reduced set that does not include attribute $c$.

Step 4: Construct the initial core attribute matrix and then form the reduced core attribute matrix

Rough set theory requires some simplification of the data to be able to arrive at overall rules. The knowledge reduction seeks to remove superfluous knowledge from information systems while preserving the consistency of classifications, which is also called attribution reduction.

The initial core attribute matrix of object can be constructed according to Equation (6).

$$
\operatorname{core}(C)=\left\{c \in C \mid \operatorname{Sig}_{C \backslash\{c\}}(c)>0\right\}
$$

Then, compare the information capacity between initial core attribute set and original conditional attribute set, and judge whether this initial core attribute set is the reduced core attribute set of information system decision table or not. The judgment rules are as follows.

(1) If $I(\operatorname{core}(C))=I(C)$, we can determine that the initial core attribute set is the reduced core attribute set, and then the reduced core attribute matrix can be formed;

(2) If $I(\operatorname{core}(C))=I(C)$, another conditional attribute with the most information significance is added into the core set (as shown in Equation (7)), and then calculate the
The conditional attribute elementary set with the missing information can be defined as:

formation content of the new conditional attribute set. If it equals to $I(C)$, the reduced core attribute matrix can be formed; otherwise, loop this step until forming the reduced core attribute matrix.

$$
\begin{array}{r}
\text { if } c_{0} \in C \backslash(\operatorname{core}(C)), \text {, let } \operatorname{Sig}_{\text {core }(C)}\left(c_{0}\right)=\max _{c \in C \backslash \operatorname{core}(c)}\left\{\operatorname{Sig}_{\text {core }(C)}(c)\right\}, \\
\text { and } \operatorname{core}(C) \bigcup\left\{c_{0}\right\} \rightarrow \operatorname{core}(C)
\end{array}
$$

Step 5: Form the discernibility matrix, and determine the final core attribute set

Discernibility matrix is an important tool in RS to express the reduction algorithm. The discernibility matrix with the missing information can be defined as:

$$
\left(c_{i j}\right)= \begin{cases}\left\{a \in A \backslash a\left(x_{i}\right) \neq a\left(x_{j}\right)\right. & \text { and } a\left(x_{i}\right) \neq * \text { and } \\ \left.a\left(x_{j}\right) \neq *\right\}, D\left(x_{i}\right) \neq D\left(x_{j}\right) \\ \phi, & D\left(x_{i}\right)=D\left(x_{j}\right)\end{cases}
$$

where $c_{i j}$ is the $i$ th-row $j$-th column element of discernibility matrix; $A$ is the conditional attribute set; $a(x)$ is the value of attribute $a$ for object $x ; D$ is the decision attribute set; $D(x)$ is the value of attribute $D$ for object $x$.

After obtaining the discernibility matrix, the matrix with only one conditional attribute element is determined as the final core attribute matrix; and then, the conditional attribute sets that not include this core attribute is converted to the final core attribute set by using the conjunctive normal form and disjunctive normal form.

The calculation flow of IRS model is as shown in Fig. 3.

\section{Case Study}

There is a $1000 \mathrm{kV}$ UHV power transmission construction project which starts at the $1000 \mathrm{kV}$ substation located in the north of Zhejiang province and ends at the $1000 \mathrm{kV}$ substation located in Fuzhou cit. This project will build three new UHV transformer substations and two $603 \mathrm{~km}$-length AC transmission lines. Due to the complicated geographical condition, high construction technical requirement, and the large resistance of land acquisition and relocation, this UHV project faces many challenges and risks.

In this paper, the object set is consisted of 15 random selected questionnaire respondents, namely $U=\left\{I_{i}, i=1,2, \cdots, 15\right\}$. The conditional attribute is $C=\left\{c_{i}, i=1,2, \cdots, 12\right\}$, which reflects the risk index attribute of UHV construction project consisted of 12 second-level risk indicators. The decision attribute is $D=\{d\}$, which reflects the overall risk situation of this UHV project construction.

The concrete calculation details of the key index 
identification of $1000 \mathrm{kV}$ UHV project construction by employing the IRS method are as follows.

Step 1: Build the information system decision table

Based on the built risk evaluation index system, the risk questionnaire can be formed, just as list in Table 1. Of which, both the likelihood of risk occurrence and the degree of risk influence adopt three-level scale standards, namely ' 1 ' represents the small likelihood of risk occurrence and low degree of risk influence; '2' represents the occasional likelihood of risk occurrence and medium degree of risk influence; ' 3 ' represents the frequent likelihood of risk occurrence and high degree of risk influence. The questionnaires were dispatched to the experts, academics and project staff. The random selected 15 questionnaire results were used to the calculation sample. Then, the risk information system decision table of UHV project construction was formed, which is listed in Table 2.

Table 1. Risk questionnaire of UHV project construction

\begin{tabular}{llllll}
\hline \multirow{2}{*}{ Risk Index } & & \multicolumn{2}{c}{ Likelihood of risk occurrence } & Degree of risk influence \\
\cline { 2 - 5 } & & frequent & occasional & small & high \\
\hline $\mathrm{P}$ & $\mathrm{p} 1$ & & \\
& $\mathrm{p} 2$ & & \\
$\mathrm{~m} 1$ & & & \\
$\mathrm{M}$ & $\mathrm{m} 2$ & & \\
& $\mathrm{~m} 3$ & & \\
$\mathrm{~T}$ & $\mathrm{t} 1$ & & \\
& $\mathrm{t} 2$ & & \\
$\mathrm{~N}$ & $\mathrm{n} 1$ & & \\
& $\mathrm{n} 2$ & & \\
$\mathrm{~S}$ & $\mathrm{~s} 1$ & & \\
& $\mathrm{~s} 2$ & & \\
& $\mathrm{~s} 3$ & & \\
\hline
\end{tabular}

Table 2. Risk information system decision table of UHV project construction

\begin{tabular}{|c|c|c|c|c|c|c|c|c|c|c|c|c|c|}
\hline \multirow{2}{*}{ Respondents } & \multicolumn{11}{|c|}{ Conditional attribute (C) } & \multicolumn{2}{|r|}{ Decision attribute (D) } \\
\hline & p1 & p2 & m1 & $\mathbf{m} 2$ & m3 & t1 & t2 & n1 & n2 & s1 & s2 & s3 & d \\
\hline I1 & 2 & 1 & $*$ & 1 & 1 & 1 & 2 & 1 & 1 & 2 & 1 & 2 & 1 \\
\hline $\mathrm{I} 2$ & 2 & 1 & 1 & 2 & 2 & 1 & 1 & 1 & 1 & 1 & 2 & 1 & 1 \\
\hline $\mathrm{I} 3$ & 2 & 1 & 1 & 2 & 1 & $*$ & 2 & 1 & 1 & 2 & 1 & 2 & 2 \\
\hline I4 & 2 & 1 & 1 & 1 & 1 & 1 & 2 & 1 & 1 & 2 & 1 & 2 & 1 \\
\hline I5 & 3 & 3 & 3 & 1 & 3 & 3 & 3 & 3 & 1 & 3 & 2 & 1 & 3 \\
\hline I6 & 3 & 2 & 2 & 2 & 3 & 2 & 3 & $*$ & 2 & 3 & 3 & 2 & 2 \\
\hline I8 & 1 & 1 & 1 & 1 & 2 & 2 & 2 & 2 & 2 & 2 & 1 & 2 & 1 \\
\hline I9 & 3 & 1 & $*$ & 2 & 1 & 2 & 2 & 1 & 1 & 2 & 1 & 2 & 1 \\
\hline $\mathrm{I} 10$ & 3 & 1 & 1 & 1 & 1 & 1 & 1 & 2 & 2 & 1 & 2 & 2 & 2 \\
\hline I11 & 2 & 2 & 2 & 2 & 2 & 1 & 2 & 2 & 2 & 3 & 3 & 2 & 2 \\
\hline I12 & 2 & 1 & 2 & 2 & 1 & 2 & 3 & $*$ & 2 & 1 & 3 & 2 & 2 \\
\hline I13 & 1 & 2 & 2 & 2 & 1 & 2 & 1 & 2 & 2 & 1 & 2 & 2 & 2 \\
\hline I14 & 1 & 2 & 2 & 2 & 1 & 2 & 1 & 2 & 2 & 2 & $*$ & 2 & 2 \\
\hline
\end{tabular}

Note: 1 . The result of $\mathrm{D}$ is calculated based on the questionnaire results in term of 'the degree of risk influence';

2. * denotes the missing data

Step 2: Determine the conditional attribute elementary set and calculate information content

According to Equation (3), the conditional attribute elementary set of UHV project construction can be obtained, which is listed in Table 3.

Table 3. Elementary sets based on similar conditional attribute values

\begin{tabular}{lll}
\hline Element set category & Element set object & Number of element set ${ }^{|X|}$ \\
\hline 1 & I1 $、$ I4 & 2 \\
2 & I2 & 1 \\
3 & I3 & 1 \\
4 & I5 & 1 \\
5 & I6 & 1 \\
6 & I7 & 1 \\
7 & I8 & 1 \\
8 & I9 & 1 \\
\hline
\end{tabular}

\begin{tabular}{lll}
\hline 9 & I10 & 1 \\
10 & I11 & 1 \\
11 & I12 & 1 \\
12 & I13 & 1 \\
13 & I14 & 1 \\
14 & I15 & 1 \\
\hline
\end{tabular}

Then, the information capacity of conditional attribute can be calculated according to Equation (4).

$$
I(C)=1-\left(\frac{1}{15^{2}}(2+1+1+2+1+1+1+1+1+1+1+1+1+1+1)\right)=0.9244
$$

Step 3: Calculate the information significance of conditional attribute

According to Equation (4), the information capacity of 
induced attribute set $C \backslash\left\{p_{1}\right\}$ without conditional attribute $\mathrm{p} 1$ can be calculated.

$$
I\left(C \backslash\left\{p_{1}\right\}\right)=1-\frac{1}{15^{2}}(2+1+2+2+1+1+1+1+2+1+1+1+1+1+1)=0.9156
$$

inflarly, the information significance of other conditional attributes can also be calculated, the results of which is listed in Table 4.

Then, the information significance of conditional attribute p1 can be calculated according to Equation (5).

Table 4. Information significant of each conditional attribute

\begin{tabular}{|c|c|c|c|c|c|c|c|c|c|c|c|c|}
\hline $\begin{array}{l}\text { Conditional } \\
\text { attribute }\end{array}$ & p1 & p2 & m1 & m2 & m3 & t1 & t2 & n1 & n2 & s1 & s2 & s3 \\
\hline $\begin{array}{l}\text { Information } \\
\text { significance }\end{array}$ & 0.0088 & 0 & 0.0088 & 0.0177 & 0 & 0.0088 & 0 & 0 & 0 & 0.0088 & 0 & 0 \\
\hline
\end{tabular}

Step 4: Construct the initial core attribute matrix and then form the reduced core attribute matrix.

Based on the Step 3 and Equation (6), the initial core attribute set can be obtained, namely $\operatorname{core}(C)=\left\{P_{1}, M_{1}, M_{2}, T_{1}, S_{1}\right\}$. According to Equation (4), we can get $I(\operatorname{core}(C))=0.9244=I(C)$. Therefore, conditional attributes $P_{1}, M_{1}, M_{2}, T_{1}, S_{1}$ are the reduced core attribute of information decision table, and the induced core attribute set is $\operatorname{core}(C)=\left\{P_{1}, M_{1}, M_{2}, T_{1}, S_{1}\right\}$. The induced core attribute matric is shown in Table 5.

Table 5. Reduced core attribute matrix

\begin{tabular}{|c|c|c|c|c|c|c|}
\hline \multirow{2}{*}{ Respondents } & \multicolumn{5}{|c|}{ Conditional attribute(C) } & \multirow{2}{*}{$\begin{array}{l}\text { Decision attribute (D) } \\
\text { d }\end{array}$} \\
\hline & p1 & m1 & m2 & t1 & s1 & \\
\hline I1 & 2 & $*$ & 1 & 1 & 2 & 1 \\
\hline $\mathrm{I} 2$ & 2 & 1 & 2 & 1 & 1 & 1 \\
\hline I3 & 2 & 1 & 2 & $*$ & 2 & 2 \\
\hline $\mathrm{I} 4$ & 2 & 1 & 1 & 1 & 2 & 1 \\
\hline I5 & 3 & 3 & 1 & 3 & 3 & 3 \\
\hline I6 & 3 & 2 & 2 & 2 & 3 & 2 \\
\hline I8 & 1 & 1 & 1 & 2 & 2 & 1 \\
\hline I9 & 3 & * & 2 & 2 & 2 & 1 \\
\hline I10 & 3 & 1 & 1 & 1 & 1 & 2 \\
\hline I11 & 2 & 2 & 2 & 1 & 3 & 2 \\
\hline $\mathrm{I} 12$ & 2 & 2 & 2 & 2 & 1 & 2 \\
\hline I13 & 1 & 2 & 2 & 2 & 1 & 2 \\
\hline I14 & 1 & 2 & 2 & 2 & 2 & 2 \\
\hline
\end{tabular}

Step 5: Form the discernibility matrix, and determine the final core attribute set

According to Equation (8), the discernibility matrix of UHV project construction can be calculated, just as shown in Table 6 .

Table 6. Discernibility matrix

\begin{tabular}{|c|c|c|c|c|c|c|c|c|c|c|c|c|c|c|c|}
\hline & I1 & I2 & I3 & I4 & I5 & I6 & I7 & I8 & I9 & I10 & I11 & I12 & I13 & I14 & I15 \\
\hline I1 & 0 & 0 & $\mathrm{~m} 2$ & 0 & $\begin{array}{l}\text { p1 } \\
\text { t1 } \\
\text { s1 }\end{array}$ & $\begin{array}{l}\mathrm{p} 1 \\
\mathrm{~m} 2 \\
\mathrm{t} 1 \\
\mathrm{~s} 1\end{array}$ & $\begin{array}{l}\mathrm{p} 1 \\
\mathrm{~m} 2 \\
\mathrm{t} 1\end{array}$ & 0 & 0 & $\begin{array}{l}\mathrm{p} 1 \\
\mathrm{~s} 1\end{array}$ & $\begin{array}{l}\mathrm{m} 2 \\
\mathrm{~s} 2\end{array}$ & $\begin{array}{l}\mathrm{m} 2 \\
\mathrm{t} 1 \\
\mathrm{~s} 1\end{array}$ & $\begin{array}{l}\mathrm{p} 1 \\
\mathrm{~m} 2 \\
\mathrm{t} 1 \\
\mathrm{~s} 1\end{array}$ & $\begin{array}{l}\mathrm{p} 1 \\
\mathrm{~m} 2 \\
\mathrm{t} 1\end{array}$ & $\begin{array}{l}\mathrm{t} 1 \\
\mathrm{~s} 1\end{array}$ \\
\hline I2 & & 0 & s1 & 0 & $\begin{array}{l}\mathrm{p} 1 \\
\mathrm{~m} 1 \\
\mathrm{~m} 2 \\
\mathrm{t} 1 \\
\mathrm{~s} 1\end{array}$ & $\begin{array}{l}\mathrm{p} 1 \\
\mathrm{~m} 1 \\
\mathrm{t} 1 \\
\mathrm{~s} 1\end{array}$ & $\begin{array}{l}\mathrm{p} 1 \\
\mathrm{t} 1 \\
\mathrm{~s} 1\end{array}$ & 0 & 0 & $\begin{array}{l}\mathrm{p} 1 \\
\mathrm{~m} 2\end{array}$ & $\begin{array}{l}\mathrm{m} 1 \\
\mathrm{~s} 1\end{array}$ & $\begin{array}{l}\mathrm{m} 1 \\
\mathrm{t} 1\end{array}$ & $\begin{array}{l}\mathrm{p} 1 \\
\mathrm{~m} 1 \\
\mathrm{t} 1\end{array}$ & $\begin{array}{l}\mathrm{p} 1 \\
\mathrm{~m} 1 \\
\mathrm{t} 1\end{array}$ & $\begin{array}{l}\mathrm{m} 1 \\
\mathrm{t} 1 \\
\mathrm{~s} 1\end{array}$ \\
\hline I3 & & & 0 & $\mathrm{~m} 2$ & $\begin{array}{l}\mathrm{p} 1 \\
\mathrm{~m} 1 \\
\mathrm{~m} 2 \\
\mathrm{~s} 1\end{array}$ & 0 & 0 & $\begin{array}{l}\mathrm{p} 1 \\
\mathrm{~m} 2\end{array}$ & p1 & 0 & 0 & 0 & 0 & 0 & 0 \\
\hline I4 & & & & 0 & $\begin{array}{l}\mathrm{p} 1 \\
\mathrm{~m} 1 \\
\mathrm{t} 1 \\
\mathrm{~s} 1\end{array}$ & $\begin{array}{l}\mathrm{p} 1 \\
\mathrm{~m} 1 \\
\mathrm{~m} 2 \\
\mathrm{t} 1 \\
\mathrm{~s} 1\end{array}$ & $\begin{array}{l}\mathrm{p} 1 \\
\mathrm{~m} 2 \\
\mathrm{t} 1\end{array}$ & 0 & 0 & $\begin{array}{l}\mathrm{p} 1 \\
\mathrm{~m} 2 \\
\mathrm{t} 1\end{array}$ & $\begin{array}{l}\mathrm{m} 1 \\
\mathrm{~m} 2 \\
\mathrm{~s} 1\end{array}$ & $\begin{array}{l}\mathrm{m} 1 \\
\mathrm{~m} 2 \\
\mathrm{t} 1 \\
\mathrm{~s} 1\end{array}$ & $\begin{array}{l}\mathrm{p} 1 \\
\mathrm{~m} 1 \\
\mathrm{~m} 2 \\
\mathrm{t} 1 \\
\mathrm{~s} 1\end{array}$ & $\begin{array}{l}\mathrm{p} 1 \\
\mathrm{~m} 1 \\
\mathrm{~m} 2 \\
\mathrm{t} 1\end{array}$ & $\begin{array}{l}\mathrm{m} 1 \\
\mathrm{t} 1 \\
\mathrm{~s} 1\end{array}$ \\
\hline
\end{tabular}




\begin{tabular}{|c|c|c|c|c|c|c|c|c|c|c|c|}
\hline I5 & 0 & $\begin{array}{l}\mathrm{m} 1 \\
\mathrm{~m} 2 \\
\mathrm{t} 1\end{array}$ & $\begin{array}{l}\mathrm{p} 1 \\
\mathrm{~m} 1 \\
\mathrm{~m} 2 \\
\mathrm{t} 1 \\
\mathrm{~s} 1\end{array}$ & $\begin{array}{l}\mathrm{p} 1 \\
\mathrm{~m} 1 \\
\mathrm{t} 1 \\
\mathrm{~s} 1 \\
\mathrm{p} 1\end{array}$ & $\begin{array}{l}\mathrm{m} 2 \\
\mathrm{t} 1 \\
\mathrm{~s} 1\end{array}$ & $\begin{array}{l}\mathrm{m} 1 \\
\mathrm{t} 1 \\
\mathrm{~s} 1\end{array}$ & $\begin{array}{l}\mathrm{p} 1 \\
\mathrm{~m} 1 \\
\mathrm{~m} 2 \\
\mathrm{t} 1\end{array}$ & $\begin{array}{l}\mathrm{p} 1 \\
\mathrm{~m} 1 \\
\mathrm{~m} 2 \\
\mathrm{t} 1 \\
\mathrm{~s} 1\end{array}$ & $\begin{array}{l}\mathrm{p} 1 \\
\mathrm{~m} 1 \\
\mathrm{~m} 2 \\
\mathrm{t} 1 \\
\mathrm{~s} 1\end{array}$ & $\begin{array}{l}\mathrm{p} 1 \\
\mathrm{~m} 1 \\
\mathrm{~m} 2 \\
\mathrm{t} 1 \\
\mathrm{~s} 1\end{array}$ & $\begin{array}{l}\mathrm{p} 1 \\
\mathrm{~m} 1 \\
\mathrm{t} 1\end{array}$ \\
\hline I6 & & 0 & 0 & $\begin{array}{l}\mathrm{m} 1 \\
\mathrm{~m} 2 \\
\mathrm{~s} 1\end{array}$ & s1 & 0 & 0 & 0 & 0 & 0 & 0 \\
\hline I7 & & & 0 & $\mathrm{~m} 2$ & $\mathrm{p} 1$ & 0 & $\begin{array}{l}0 \\
\text { p1 }\end{array}$ & 0 & 0 & 0 & 0 \\
\hline I8 & & & & 0 & 0 & $\begin{array}{l}\mathrm{p} 1 \\
\mathrm{t} 1 \\
\mathrm{~s} 1\end{array}$ & $\begin{array}{l}\mathrm{m} 1 \\
\mathrm{~m} 2 \\
\mathrm{t} 1 \\
\mathrm{~s} 1\end{array}$ & & $\begin{array}{l}\mathrm{p} 1 \\
\mathrm{~m} 1 \\
\mathrm{~m} 2 \\
\mathrm{~s} 1\end{array}$ & $\begin{array}{l}\mathrm{m} 1 \\
\mathrm{~m} 2\end{array}$ & $\begin{array}{l}\mathrm{p} 1 \\
\mathrm{~m} 1 \\
\mathrm{~s} 1\end{array}$ \\
\hline I9 & & & & & 0 & $\begin{array}{l}\mathrm{m} 2 \\
\mathrm{t} 1 \\
\mathrm{~s} 1\end{array}$ & & $\begin{array}{l}\mathrm{p} 1 \\
\mathrm{~s} 1\end{array}$ & $\begin{array}{l}\mathrm{p} 1 \\
\mathrm{~s} 1\end{array}$ & $\mathrm{p} 1$ & $\begin{array}{l}\mathrm{p} 1 \\
\mathrm{~s} 1\end{array}$ \\
\hline I10 & & & & & & 0 & 0 & 0 & 0 & 0 & 0 \\
\hline I11 & & & & & & & 0 & 0 & 0 & 0 & 0 \\
\hline I12 & & & & & & & & 0 & 0 & 0 & 0 \\
\hline I13 & & & & & & & & & 0 & 0 & 0 \\
\hline I14 & & & & & & & & & & 0 & 0 \\
\hline I15 & & & & & & & & & & & 0 \\
\hline
\end{tabular}

From the discernibility matrix, the conditional attributes $\mathrm{p} 1$, $\mathrm{m} 2, \quad \mathrm{~s} 1$ are the final core attributes. The conditional attribute sets that do include the final core attributes are $\{\mathrm{M} 1, \mathrm{~T} 1\}$. The conditional attribute combination free of final core attribute is displayed in the form of conjunctive normal form, namely $P=\left\{M_{1} \vee T_{1}\right\}$, and then is transformed by disjunctive normal form to be $P=\left\{M_{1}\right\} \vee\left\{T_{1}\right\}$. Therefore, $\left\{P_{1}, M_{1}, M_{2}, S_{1}\right\}$ and $\left\{P_{1}, M_{2}, T_{1}, S_{1}\right\}$ can be considered as the reduced attribute set of risk identification of UHV project construction.

From the calculation result, we can see that 'land requisition and logging policy risk', 'security management risk' and 'land requisition, removing and crop compensation risk' are the key risk indicators of this UHV project construction, which should be mainly focused on when managers perform the risk management and control on this project.

\section{Conclusions}

In this paper, the key risk indicators are identified by employing the IRS model with the introduction of 'information capacity' concept, which can identify the key risk index when including the missing information in the index system. Taken a certain $1000 \mathrm{kV}$ UHV project as the example, the key risk indicators were identified. The following conclusions can be safely drawn:

(1) 'land requisition and logging policy risk', 'security management risk' and 'land requisition, removing and crop compensation risk' are the key risk indicators of this UHV project construction, which should be mainly focused on when managers perform the risk management and control on this project;

(2) The risk index sets \{land requisition and logging policy risk, goods and material management risk, security management risk, land requisition, removing and crop compensation risk\} and \{ land requisition and logging policy risk, security management risk, substation construction risk, land requisition, removing and crop compensation risk $\}$ can be used as the reduced index system of UHV project construction, which simplifies the risk index system and risk evaluation calculation under the premise of preserving vital information.

\section{Acknowledgements}

The authors thank the editor and reviewers for their comments and suggestions.

\section{References}

[1] Liu Zhenya. China's electricity and energy M] .Beijing: China Electric Power Press, 2012

[2] Zhao H, Guo S. Risk Evaluation on UHV Power Transmission Construction Project Based on AHP and FCE Method [J]. Mathematical Problems in Engineering, 2014, 2014.

[3] Wei Minghua, Lu Shibao, Zheng Zhihong. Risk analysis on construction of agricultural water conservancy projects [J]. Transactions of the CSAE, 2011, 27(Supp.1): 233-237.

[4] Huang Hong-wei, Zhu Lin, Xie Xiong-yao. Risk assessment on engineering feasibility of key events in Shanghai metro line No. 11 [J]. Chinese Journal of Geotechnical Engineering, 2007, 29(7): 1103-1107.

[5] Xu Wei-ping, Wang Xiu-ying. Environmental risk assessment of oil field pipeline construction project based on mutation series method [J]. Chinese Journal of Systems Science, 2012, 20(1): 89-93.

[6] Zhou Li-sha, Li Chen, Yu Shun-kun. System dynamics simulation research on project management model for china's smart grid [J]. East China Electric Power, 2012, 40(1): 31-34. 
[7] Zhang Qiang, Wang Ning. Application of network management system for project files in power grid construction [J]. Power System Technology, 2007, 31(S2): 83-86.

[8] Guo Ri-cai, Xu Zi-zhi, Qi Li-zhong, et al. General situation of typical transmission line design in usa and its enlightenment to design and construction of power grids in china [J]. Power System Technology, 2007, 31(12): 33-41.

[9] Guo Ri-cai, Yuan Zhao-xiang, Li Bao-jin. A survey on typical design of substations in france and korea and relevant suggestion to power network engineering in china [J]. Power System Technology, 2006, 30(6): 73-76.

[10] An lei, Wang Mian-bin, Tan Zhong-fu. Risk assessment model based on set pair-fault tree method for power transmission project [J]. East China Electric Power, 2011, 39(1): 12-18.

[11] Wu Yunna, Liu Yarui, Wang Weibing. Risk factor analysis on power grid transmission and transformation project [J]. China Rural Water and Hydropower, 2009, (2): 133-139.

[12] Wang Liping, Wang Xiaoru. Differential protection based on calculated power for uhv transmission lines $[\mathrm{J}]$. Proceedings of the CSEE, 2013, 33(19): 174-182.

[13] Xie Qiang, Li Jiguo, Yan Chengyong, et al. Wind tunnel test on wind load transferring mechanism in the $1000 \mathrm{kV}$ UHV transmission tower-line system [J]. Proceedings of the CSEE, 2013, 33(1): 109-116.

[14] GAO Shuang, DONG Lei, GAO Yang, et al. Mid-long term wind speed prediction based on rough set theory $[\mathrm{J}]$. Proceedings of the CSEE, 2012, 30(1): 32-37.
[15] Wang Gang, Luo Huihui, Huang Min. A rough-set based detection method for detuning components in a triple-tuned DC filter[J]. Automation of Electric Power Systems,, 2011, 35(20): 81-87.

[16] Zhang Zhiyi, Yuan Rongxiang, Yang Tongzhong, et al. Rule Extraction for Power System Fault Diagnosis Based on the Combination of Rough Sets and Niche Genetic Algorithm [J]. Transactions of China Electrotechnical Society, 2009, 24(1): 158-163.

[17] Su Hong-sheng, Li Qun-zhan. Substation fault diagnosis method based on rough set theory and neural network model [J]. Power System Technology, 2005, 29(16): 66-70.

[18] Liu Si-ge, Cheng Hao-zhong, Cui Wen-jia. Optimal model of multi-objective electric power network planning based on rough set theory $[\mathrm{J}]$. Proceedings of the CSEE, 2007, 27(7): 65-69.

[19] Bai C, Sarkis J. Green supplier development: analytical evaluation using rough set theory [J]. Journal of Cleaner Production, 2010, 18(12): 1200-1210.

[20] Liang J., Shi Z., Li D.. Information entropy, rough entropy and knowledge granulation in incomplete information systems [J]. International Journal of General Systems, 2006, 35 (6): 641-654. 